\title{
Paget Disease of the Anal Canal
}

National Cancer Institute

\section{Source}

National Cancer Institute. Paget Disease of the Anal Canal. NCI Thesaurus. Code C7477.

Paget disease involving the squamous epithelium of the anal canal. 